\title{
COMMUNITY EDUCATION INITIATIVES
}

\author{
Rekha Shahani \\ Initiatives of Change (IofC) India, India \\ shahani.re@gmail.com
}

\begin{abstract}
India is a pluralistic and a complex society in terms of its regional, religious, linguistic, castes and economic divides. There are the urban-rural as well as gender differences. Education too has different offerings. There has been progress in terms of literacy rate, but yet there remains a challenge when it comes to equity in education. Quality education also remains a challenge especially when it comes to educating a large population. Although education strives to meet the needs of all but formal systems cannot do it all. Therefore initiatives have to be taken up by conscientious educators and reach out to the community to 'educate' the young for becoming good human beings.
\end{abstract}

Keywords : Quality Education, Formal System, Good Human Beings

\section{IMPORTANCE OF EDUCATION AND COMMUNITY DEVELOPMENT}

The purpose of education is to awaken and enlighten the human being for bringing about positive changes in one's surroundings, starting with one's home, neighbourhood and the world. Being associated with Kamala High School, Mumbai, my focus was the surrounding community served by it. The school had many $1^{\text {st }}$ generation learners whose parents had never been to any school or college. They were the ones who did not know reading or writing but had great aspirations to make their children $1^{\text {st }}$ class citizens of the country and the world. It is for these reasons they sent their children to an English medium school. The parents of children were mostly of daily wage workers, carpenters, cobblers, drivers, maid servants, carpenters, tailors, and vegetable and fruit vendors.

\section{NEED FOR COMMUNITY INITIATIVES AND INTERVENTIONS}

As members of the community the students and their parents were made to understand the need and importance of education for all. Although the children did not like it when their elders came to school where they were studying, but soon understood that their parents too needed to be educated. Interaction with students and parents indicated that there is a need to conduct programs that improved personal lives and promoted healthy behaviors.

It was therefore, essential to develop literacy, skills and values among them. Classes were started in the school premises for the mothers, grandmothers, sisters and sisters in law of those children who came to school. It was not an easy task, but gradually picked up. Personal experience of the researcher/teacher/principal too was a motivating factor in initiating programs for community development.

\section{QUESTIONS}

1. Can educating the community help in enhancing learning and social development of individuals and groups?

2. Can conscientious educators reach out to the community to 'educate' the teachers, and school leaders as well as the students and their parents to help the young become good human beings?

3. The answer to these questions lay in the meeting of the minds who would volunteer to come forward and give their time, efforts and spend money in designing and conducting programs. These programs would include, workshops where hands on experience could be given to the participants.

4. With support from volunteers who became actively involved and with collaboration with private and government agencies, programs were designed and conducted for teachers, students and the youth, parents, and members of the community. Efforts were made to include all. 


\section{THE INITIATIVES}

\section{For Teachers}

'Initiatives of Change India' has launched the programme 'Education Today Society Tomorrow' (ETST) for teachers and school leaders. This programme helps educators to introspect and make positive changes in their own thoughts, beliefs and actions, thus becoming inspiring role models for their students, parents and the community at large.

Thousands of teachers have gone through this life changing programme in rural and urban India, over the past 25 years.

Through 'Education Today, Society Tomorrow' (ETST), we have worked with the teachers in the villages of India - empowering them to be better teachers by focusing on self and later on the various skills needed to be good teachers. Working on relationships, listening to your inner voice, writing it down in your journal your deposits and withdrawals toward your family, friends and community made the teachers realize their role in the society.

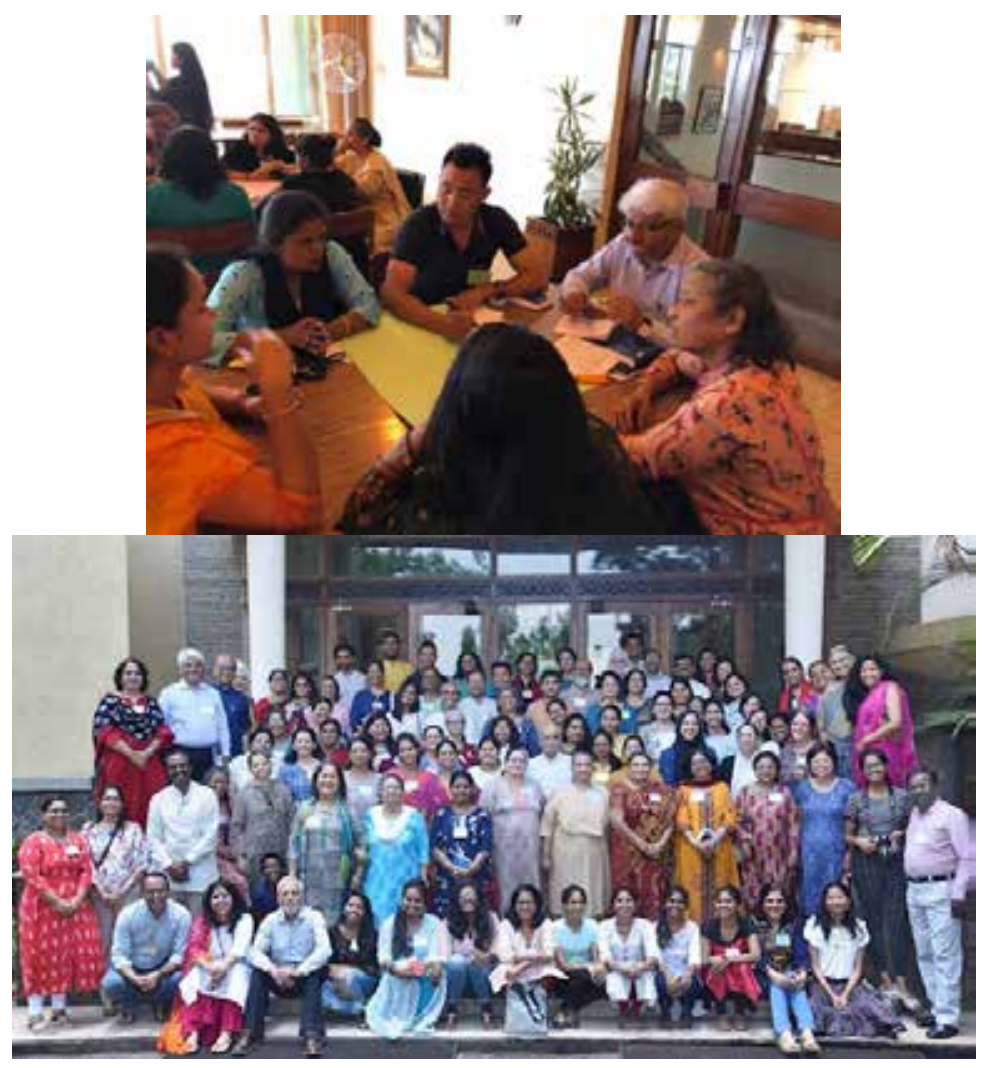

\section{For Students and Youth}

'The Public Concern for Governance Trust (PCGT) Mumbai' has been making its contribution to education in various ways. Through its 'KUCHH AUR' programme ('Kuchh Aur' means something more-i.e. beyond the routine academics), it reaches out to the socio-economically challenged students enrolled in Municipal Schools. The aim is to build a strong foundation in values such as discipline, hard work, compassion, and servant leadership. Under the aegis of 'KUCHH AUR' sessions have been conducted in different communities like Rabale, along with Ramesh Cori, M. G. Nagar in collaboration with Children of the World. Until now 300 lives every month have been touched upon. I visited the neighboring communities to encourage so that the children could come to school.

Workshop sessions on values such as compassion, honesty, love, kindness, relationship, gender equality, respect for religious diversity, spiritual oneness, and many more fun activities as ice breakers were have been also conducted. The schools participating in these were Kamala High School, Sardar Vallabhbhai Patel Vividhlaxi Vidyalaya and Puroshottam High School in Mumbai. Children who participated in the activities conducted by us have now got their own families and are ensuring that they are disciplined and educated. 


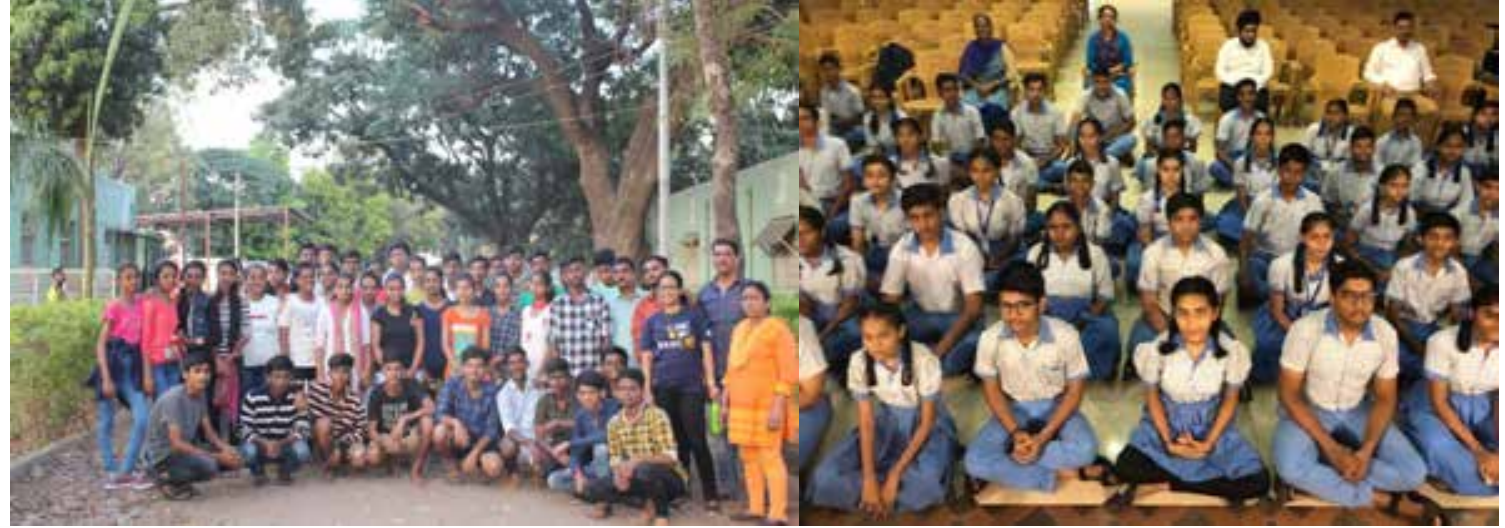

India being a socially and culturally diverse country CELEBRATING RELIGIOUS DIVERSITY AND SPIRITUAL ONENESS has to be a part of their overall education. For this every day the students would recite prayers and scriptures from various religions. This helped in opening the hearts of every student and teacher towards friends of other faiths. This in turn affected their interaction within the family and community. Another activity 'Quiet Time' helped the students and teachers to reflect and introspect without making any judgments. Accepting everyone the way they were created harmony, respect and love amongst communities. This eliminated biases or prejudices.

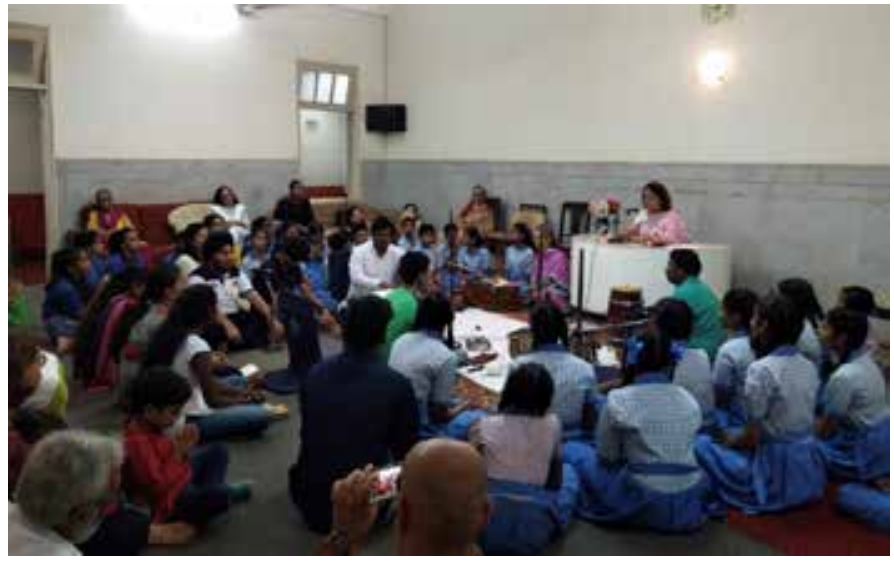

'DEAR TIME' was another activity encouraged every day. During the school hours the students are given time for reading. It is an acronym for 'Drop Everything and Read'. This reading is not academic but focuses on learning about the world and the society. It could also be reading stories and biographies of great men and women. This has helped developing reading habit among students. This in turn encouraged parents to buy books for their children. This activity helped keep children away from their phones and television, as they were encouraged to read at home along with their family members. Focus was also on vocabulary building and pronunciation. For this the students were encouraged to use the dictionary.

\section{For Parents}

Between 1990 till date - more than 5000 students and their families have benefited with the kind of education we were providing. Working in the local communities helped them to learn about health, hygiene, sanitation, food, nutrition, vaccination, besides being literate or going to school. How to be honest in their local business was taught to the parents. Not to litter or spit and keep the surrounding clean was also taught to them. Simple activities of washing their hands with soap and water and cutting their nails improved their health and stopped diarrhea in the communities to a great extent. We have also conducted sessions with mothers on relationship management, anger control and happiness. Programs with the aim of making mothers literate, teach them skills of their choice and make them a champion in the same were also taken up.

Conducting workshop for parents made the male members of the family give up smoking, drinking and many of the addictions. Volunteers were assigned so as to see that recurrence of the same addiction does not take place. Since last two years we are conducting sessions in community and we indirectly touch the families. We visited communities so that they can accept us as family. 


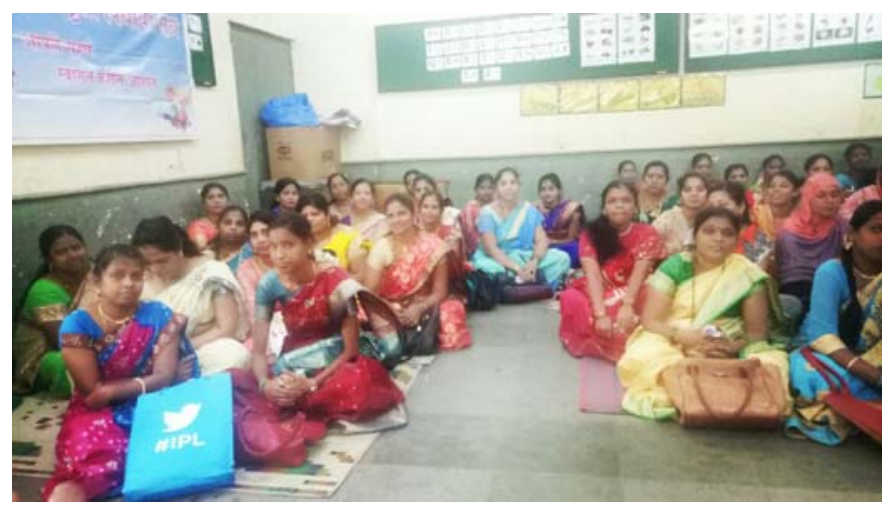

Another important activity that we engaged in was COFFEE WITH THE PRINCIPAL Parents of different students would meet the principal on every Tuesday morning and share about the child studying in the school. The objective of this activity was to listen to the parents without interruption, say only good things about the child to the parents, get to know the child through the parents, and ensure that the parents went home happy as no negative things were conveyed to the parent by the principal. This weekly activity motivated the teachers also to invite the parents, get to know their students better and stop complaining of what the student was not doing. Tea and the coffee were served by the students themselves and they took great pride by serving their parents. This activity also gave the parents the confidence in the school and they felt welcomed as they were invited by the principal and they felt confident in the functioning of the school.

\section{For Members of the Community}

The PCGT periodically holds soft skills training programs for the police personnel who are serving the 20 million strong population of Mumbai. The PCGT also engages with university students by conducting the National Youth Parliament and seminars for creating awareness about the Right to Information Act. (RTI is an Act of Parliament which mandates timely response to citizens' request of government information).

Camps have been arranged for the community youth so that they can understand other cultures and their problems.

We conducted workshop with the youth on civil defence and disaster management. This enabled and empowered the youth to help others in emergency situations. Through stories and anecdotes we interacted with the youth, about civic issues and how we can solve them. Sessions on the environmental issues were also a part of our initiative. The role of the youth was highlighted thereby creating awareness in them. Making and use of cloth bags by the members of the community was encouraged.

Opening of community library also become an important mission for us. We collected good books and started libraries in various communities. Later more and more people helped with books for students in higher education. As such we could not only support school or community education but also students at under graduation and post-graduation levels.

Gender equality is another issue that is to be understood by the youth today. Inculcating respect for the opposite gender was focused upon in many of the sessions. Women must be empowered in their own way. They should get the chance to make their own decision and be given equal opportunities. It is our endeavor that in our India, there should be no such words like minority groups, weaker sections or people of backward classes.

The youth were initiated into issues on freedom of expression, freedom to express desire and ways in which to contribute for the development of one's country through inclusive growth was lways discussed through dialogue and brain storming.

\section{COLLABORATION}

Collaborating with private, State and Government institutions, gave an exposure to the real world of education in our country. The private schools realized the good work being done by the government schools and best practices were shared so that all the stake holders could benefit.

School exchange programmers locally and nationally were organized under ETST so that the youth of today gets an exposure to build rapport through team building games and raise their self-esteem in spite of all the difficulties. 


\section{INCLUSION: A WAY OF LIFE}

Today there is a huge clamor for inclusion. Making all included in the mainstream despite their economic condition, physical disability, learning disability, gender differences, was something I worked on right from the beginning. The purpose was to teach them with love and compassion. This made me admit children who were blind, spastic, or those suffering from learning disabilities. This made the other students more compassionate and sensitive towards the needs of others. Many normal students would become writers for these children with disability, and many volunteered their time and expertise with Non-Governmental Organizations (NGO'S), so that they could serve others with disabilities.

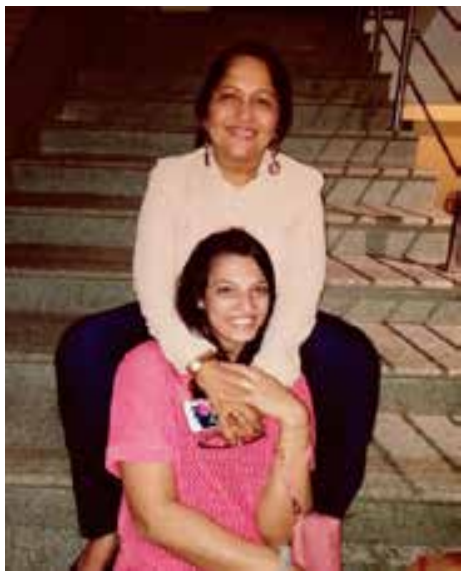

\section{SHARING SOME INDIVIDUAL CASES}

Dr. Pankaj Pathak came to me when he was in Kindergarten. His father was an uneducated auto rickshaw driver. It was Pankaj's dream to pursue higher studies and attain the highest degree. He focused on his goal and took scholarship from school and outside agencies. He completed his Doctorate and achieved his dream. Today he is holding a PHD degree and living the reality.

Prof. Promod Kumar Gupta came to me when he was a 10 year old boy. He was not very good in academics. Today he is working with School of Biotechnology and Bioinformatics, at D Y Patil Deemed to be University in Mumbai. He has contributed a number of chapters in books and research articles in national and international publications. He is working in the field of "Protein Kinase and drug discovery". He learnt all this while we were focusing on community welfare, conducting various educational programs. Today his area of research is in small molecule designing of anti-cancer drug, metabolism pathway modeling and analysis.

Mr. Shaikh credits his achievements to Kamala High School. Getting admitted to an English medium school was a great achievement for his parents. With motivation and encouragement from his teacher cum mentor Shaikh evolved into a confident and thinking individual with belief in self. Focus was not just on academics but beyond the classroom, where opportunities for exploration and developing of communication skills was encouraged. Gradually from roll no.3 to Mr. Shaikh earning a six figure salary, he made lasting friendships for life too.

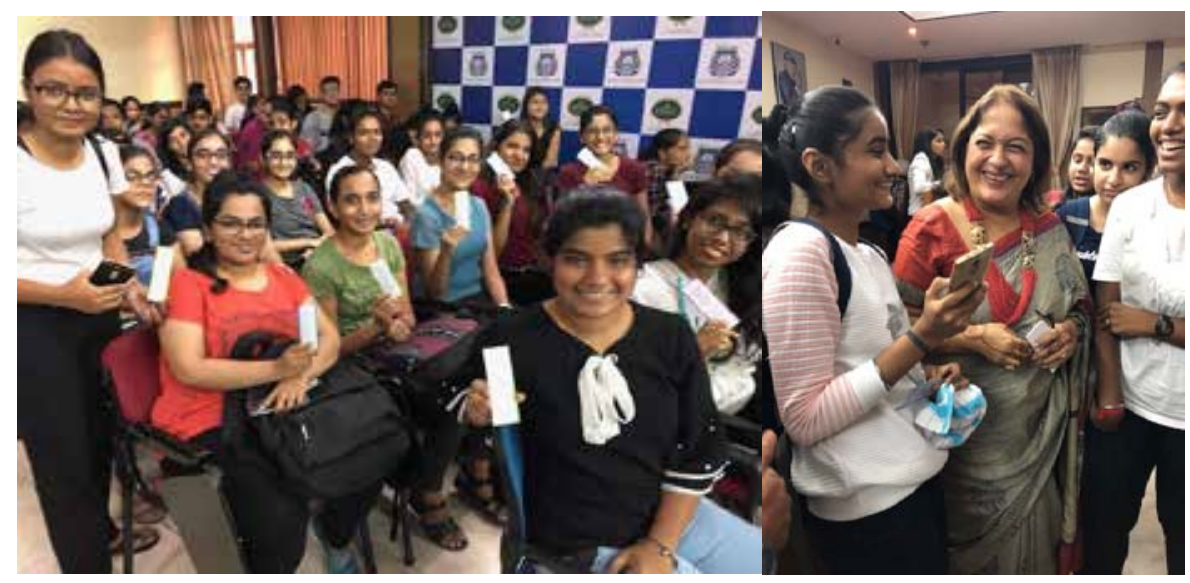




\section{CONCLUSION}

It does not matter from where the children came, but I surely wanted to know where they are going once they become young adults. The focus of Initiatives of Change India, Education Today Society Tomorrow and Public Concern Government Trust has been to transform the lives of the youth, create in them awareness about their duties as responsible citizens.

\section{REFERENCES}

UNICEF (2013) India Literacy Rate

Public Concern (October 2019): the Quarterly Newsletter of Public Concern for Governance Trust (PCGT)

World Bank (2014) Education in India

World Bank (2014) World Development Indicators: Participation in Education 